Hofmann as non-resident Assayer to the Royal Mint, but was deprived of the appointment by Mr. R. Lowe, who abolished the office in 1870 .

A pupil of Graham and Liebig, he had all their enthusiasm for scientific investigation, and devoted nearly the whole of his time to research work in the domain of organic chemistry: the eminence he attained in this branch of science is fully recognised, but his contributions to our technical knowledge are not so well known. $\mathrm{He}$ was the author of many ingenious and useful inventions in relation to dyeing, sugar manufacture, tanning, \&c., but the greatest and most permanent has been the application of charcoal for disinfecting and deodorising purposes, which took the form of charcoal air-filters for the ventilation of sewers, and the charcoal respirator, the best of all respirators, not only for preventing the deleterious effects of noxious gases in numerous manufacturing operations, but also for the protection of those subject to bronchitis, asthma, and other similar diseases.

It is impossible in our limited space to give even an outline of the numerous investigations which he published during his long scientific career, extending as it did over a space of more than forty years. The results are embodied in about 100 papers, published in various scientific journals, English and foreign ; they relate in great part to what may truly be called "organic chemistry"...the chemistry of carbon compounds formed by organised bodies. John Stenhouse was LL.D. of Aberdeen; a Fellow of the Royal Society, which awarded him the Royal Medal in $187 \mathrm{I}$; one of the founders of the Chemical Society; and a Fellow of the recently-established Institute of Chemistry. Of his personal character those who knew him intimately could never speak too higbly; his death will be felt and mourned not only by his many personal friends, but also by men of science throughout Europe.

\section{WILHELM HEINTZ}

$\mathrm{W}^{\mathrm{B}}$

E recently recorded the death, at Halle, on December r, of Prof. W. Heintz, one of the leading German chemists of our day. He was born at Berlin, November 4 , 1817. His earlier university studies were undertaken with a view of becoming a pharmacist, but this intention was relinquished as the attractions of a more purely scientific career were offered to him. In 1844 he received the doctor's degree at the Berlin University, and two years later he was admitted as privat-docent in the philosophical faculty of the same university. In $185^{\circ}$ he accepted a call to Halle as the successor of the wellknown Marschand; and here, after passing frve years as an extraordinary professor, he was appointed in 1855 to the full professorship of chemistry, and the directorship of the newly-built laboratory, posts which he occupied at the time of his death.

As a teacher and as a guide to students inclined towards chemical research, Prof. Heintz evinced more than ordinary capacity, and for a quarter of a century he has ably maintained the reputation of Halle among the centres of chemical interest in Germany. This reputation is due in no small part to his own personal contributions as an investigator ; for few chemists of our day have manifested such unwearied energy and long-continued application, such thoroughness of work, accuracy of observation, and widespread familiarity with fact and theory as are evinced in Heintz's manifold and diversified researches.

The earlier portion of his career was directed to the solution of problems in physiological chemistry. Among his more important researches in this direction mention should be made of those on the juice of the Galactodendron (1845), on kreatin and kreatinin (1847), on lactic acid in the gastric juice (1849), on the composition of bones, and on cholesterin (I850), on the colouring matter of gall stones (185I), on urinary sediments (1862), and more especially on the animal and vegetable fats. This latter research, extending over a period of about seven years, includes exhaustive studies on the physical properties of the fats, methods of their separation, their chemical constitution and nature, the products of their decomposition, \&c. His careful observations of the melting points and composition of the fatty acids in the pure state and when mixed with each other, form essentially the basis of our present knowledge on this subject, and enabled him at the time to show the composite character of various fats which preceding chemists had regarded as.pure compounds.

In analytical chemistry Heintz devised a variety of methods and modifications of methods, amongst which mention may be made of his contributions on the estimation of sulphur in organic bodies, on the separation of magnesia from the alkalies, on the analysis of ashes (1847), on the determination of urea and uric acid, on the detection of gall ( 1848 ), on the determination of nitrogen (185 1 ), on the estimation of phosphoric acid, and numerous analytical data.

In inorganic chemistry his researches were chiefly confined to studies on a variety of phosphates, on bismuth and uranium salts, on the preparation of cæsium and rubidium compounds (1865), on the combustion of ammonia in oxygen (1864), on the silicates of the alkaline metals, and to the examination of the minerals margarite, stassfurtite, carnallite, aluminite, and boracite, the latter of which he prepared artificially (1860).

It is however in the field of pure organic chemistry that Heintz's discoveries have been most numerous and important. They commence with his investigation on saccharic acid, begun in 1844 and resumed in $1858-1860$, to which we owe a great measure of our knowledge of this acid, and especially of its salts and ethers. This was followed in 1856 by a study on the action of chloride of sulphur on the salts of organic acids, in which he recorded the unvarying and simultaneous formation of chlorides and sulphates at the expense of the organic salts. In 1859 he began his extensive research on glycollic acid, which occupied much of his time until i872, by exposing monochloracetic acid to the action of various sodium alcoholates, obtaining thereby the different ethers of glycollic acid; thus with sodium ethylate:

$$
\mathrm{CH}_{2} \mathrm{Cl} . \mathrm{COOH}+\mathrm{NaOC}_{2} \mathrm{H}_{5}=\mathrm{NaCl}+\underset{\mathrm{COOH}}{\mathrm{C} \mathrm{H}_{2} \cdot \mathrm{OC}_{2} \mathrm{H}_{5}} \text {. }
$$

By means of this prolific reaction he obtained a number of interesting derivatives of the acid in question. Closely allied to them were the acid ethers of glycollic acid, obtained by submitting monoshloracetic ethers to the action of salts, or by acting upon glycollic ethers with such bodies as phosgene or chlorocarbonic ether. Among the other important compounds discovered by him in this group are glycolamide, glycol-ethyl-amide, diglycollic acid-- $\mathrm{O}\left(\mathrm{CH}_{2} . \mathrm{COOH}\right)_{2}$-obtained by the action of sodium hydrate on monochloracetic acid, diglycoll-diamide, diglycollamic acid, \&c. During this same period he made noteworthy investigations on the ethyl-amines, on sulphocyan-acetic acid and its derivatives, on nitrate of ethyl, on ethyl-hydantoïn, on lactic acids, and on the amido-acids obtained from chloropropionic and iodopropionic acids by the action of ammonia. With 1874 commences his last important rejearch-that on the aceton bases, the simplest of which result from the action of ammonia on aceton. While forced to overcome manifold difficulties in the prosecution of this investigation, Heintz succeeded in isolating a number of novel and important compounds, especially interesting from a theoretical point of view. The leading forms embraced in this new group are diacetonamine, triacetonamine; the corresponding alcohol bases diaceton-alcamine and 
triaceton-alcamine ; benzal-diacetonamine ; amido-trimethyl-oxybutyro-nitrile resulting from the action of prussic acid on diacetonamine; and amido-dimethyl-acetic acid, obtained by the oxidation of diacetonamine; while a paper published a few months since describes a new aceton base containing sulphur. Prof. Heintz's activity was manifested up to within a few months of his death. In addition to the paper just alluded to his contributions to chemical literature during the year just closed include articles on triaceton-diamine, on the existence of acetonine, on two compounds of urea with chloride of gold, and on diethidene lactamic acid.

Prof. Heintz was the recipient in 1862 of thehotorary degree of M.D. from the University of Königsberg in recognition of his services to physiological chemistry. In 1876 he was elected an honorary member of the London Chemical Society.

T. H. N.

\section{SMOKE ABATEMENT}

$A$ MEETING was held in the Egyptian Hall at the Mansion House on Friday last, under the presidency of the Lord Mayor, to consider the best means of remedying the evils arising from the present smoky condition of the atmosphere of London. Among those present were Mr. G. J. Shaw-Lefevre, M.P. (First Commissioner of Works), Mr. W. Spottiswoode (President of the Royal Society), Dean Stanley, Sir U. Kay-Shuttleworth, Dr. Farquharson, M.P., Mr. Ernest Hart (Chairman of the joint committee of the Health and Kyrle Societies), Col. Festing, R.E., Dr. Alfred Carpenter, and Prof. Chandler Roberts.

Mr. Ernest Hart, in explaining the objects of this movement, said that some practical advance had already been made. It was not pretended that fogs could be prevented; but since smoke added opaquenes; and corrosive and other deleterious qualities to London fogs, much might be done to diminish the discomforts and evils we suffered from this cause. Having described the objects proposed to be attained by an exhibition of apparatus and smokeless fuel, he gave the results of some calculations in order to bring home to the minds of his hearers the enormous waste of money involved in the present arrangements for heating houses.

Mr. Spottiswoode stated that a committee of the Royal Society had been appointed to investigate the facts connected with the formation of fog; but while we looked to science to tell us what was wanted to improve our atmosphere, we looked to the legislature to carry out those effectual preventive measures which all hoped would some day or other be devised. Nevertheless, without the strenuous aid and co-operation of every householder the best legislation could be turned to but little account. In conclusion he moved, "That it is the opinion of this meeting that the smoky condition of the atmosphere of London injuriously affects the health and happiness of the community, besides destroying public buildings, deteriorating perishable fabrics, and entailing in various ways unnecessary expenditure."

Sir Frederick Pollock seconded the resolution, and urged that much might be done if every one who had an old fire-grate to replace would provide one of an approved and really more economical pattern.

Mr. G. J. Shaw-Lefevre moved, "That this meeting is further of opinion that the injurious effects of fog are largely due to the quantities of smoke given forth from the chimneys of furnaces, manufactories, and steamvessels, as well as dwelling-houses, and that the smoke in the metropolis might, without any considerable difficulty, be greatly lessened by the better enforcement of the existing law, by the introduction of amended legislation, and by the general use in all descriptions of premises, including dwelling-places, of proper smoke-preventing apparatus, improved household stoves and grates, or of smokeless fuel." As the head of the public department responsible for the public works of this great metropolis, he need hardly assure those present that he was deeply impressed with the importance of the subject under discussion. The importance of pure water was often insisted upon, but surely pure air was even more important. Yet, for years past, it must be admitted that the air of London had been getting worse, and fogs were denser and of longer duration than formerly, even invading the summer months. There could be no doubt that forty or fifty years ago London was famous for its roses; now it was impossible to get the rose to blossom here, and it was all but impossible to get any of the conifers to grow in the darkness of the London atmosphere. He should, however, deprecate any hasty attempts to legislate. Much might be done by the extension of the existing Acts relating to the abatement of the nuisance from smoke, and he thought Government might be rightly called upon to give some additional facilities for the purpose of enforcing those Acts. It was monstrous that in these days so many factories should not be consuming their own smoke, and, since there was a great economy in the use of appliances which prevented this waste of fuel, there was no hardship in enforcing the Act. When they came to the question of the domestic consumption, he thought it would not be wise to attempt to interfere by any legislation. They must rather trust to persuasion and example and inducements. His own hope was in the introduction of scme other heat-giving apparatus. Doubtless the substitution of anthracite for northcountry coal would be an advantage; but he did not see the means of persuading the enormous mass of householders to use the smokeless coal unless it could be distinctly proved to them that there would be economy in the change. He would suggest that it might be worth while for the gas companies to turn their attention to the production of gas for heating purposes. He could not help thinking that the time was not very far distant when not only our streets and public buildings, but also our private houses, would be lighted by electricity. There were non-luminous gases suitable for heating purposes, which might be made at a much less cost than the gas at present supplied for lighting. From a friend he had learnt that water-gas, which could be made at a low rate, was used in many towns in America for heating purposes. Every one could do something to help forward this good work of abating smoke, and for himself he would promise to use his efforts in the department with which he was connected to diminish the nuisance from smoke. When he mentioned that some 20,000 tons of coal were purchased annually by the department, the meeting would appreciate the extent to which the public offices added to the smoke in the atmosphere of the metropolis. $\mathrm{He}$ hoped the time would not be far distant when they would have restored the atmosphere of London to its early purity, the blossom to our London roses, and the bloom to the cheeks of our London children.

Dr. Alfred Carpenter urged that this was a question particularly affecting the middle class and the poor, the waste of fuel at present being deplorable. He moved "That this meeting approves the proposal of the joint Committee of the National Health and Kyrle Societies to hold an exhibition, by permission of Her Majesty's Commissioners for the Exhibition of $185 \mathrm{I}$ and the other authorities, in buildings erected for the International Exhibition of 1862 , of the various smokeless coals and other fuels, and of various appliances applicable to household and manufacturing purposes for the reduction of smoke, and to test the same, in order to demonstrate for public information the means practically available to secure that object. This meeting is of opinion that the investigation and testing should precede any application for amendment of the existing Smoke Acts, or for new legislation in regard to smoke from du elling-houses." 